\title{
Conflict Resilience and the Image of the Other among North and South Koreans
}

\section{Borislava Manojlovic}

The Carter School for Peace and Conflict Resolution, George Mason University, https://carterschool.gmu.edu/

\begin{abstract}
The article aims to articulate key micro-level factors that contribute to the resilience to conflict of South and North Korean communities living in the Seoul metropolitan area. The concept of resilience at the micro-level is defined as having three aspects: recognition of communal and individual interdependence, quality of interaction, and perceptions promoting cooperation and trust. The problem-solving workshop conducted with North Korean diaspora members and their South Korean counterparts served as an opportunity to assess communal resilience to conflict. The findings show that resilience may improve by enabling quality interaction among community members and the introduction of education that promotes understanding, tolerance, and respect.
\end{abstract}

Keywords: conflict resilience, problem-solving, North Korea, South Korea.

\section{Introduction}

The article aims to articulate key micro-level factors that contribute to the resilience to conflict of South and North Korean communities living in the Seoul metropolitan area. The ideologically, socially and economically diverse communities represent a microcosm of the challenges and opportunities that may emerge with the integration of the two Koreas. The concept of resilience to conflict is observed through a dynamical systems lens. Specifically, the nested model of components of sustainable peace ${ }^{1}$ is used to look at micro-level factors for resilience to destructive conflicts. The concept of resilience at the micro-level is de-

1 Robin R. Vallacher, Peter T. Coleman, Andrzej Nowak, Lan Bui Wrzosinska, Larry Liebovitch, Katharina Kugler, and Andrea Bartoli, Attracted to Conflict: Dynamic Foundations of Destructive Social Relations (New York: Springer, 2014). 
fined as having three aspects: 1) recognition of communal and individual interdependence; 2) quality of interaction; and 3) perceptions promoting cooperation and trust. The problem-solving workshop (PSW) conducted with North Korean diaspora members, and their South Korean counterparts served as an opportunity to assess communal resilience. The exercises and survey of the participants during the problem-solving workshop provided insights into the communal resilience of the two communities that are facing challenges of socio-economic integration and negative perceptions towards each other.

The workshop took place in Songdo, South Korea, with 14 participants that belonged to North and South Korean communities living in South Korea. Although communal resilience requires a longitudinal and multi-level study, this article offers a glimpse into the participants' perceptions generated via survey and problem-solving exercises. The problem-solving workshop focused on identifying issues that communities faced in their everyday interaction, how they dealt with differences, and addressed the problems. The findings show some preliminary insights into the ways communities could become more resilient to conflict through quality interaction among community members and the introduction of education that promotes understanding, tolerance, and respect.

\section{Problem-Solving Workshops}

From September 28-29, 2019, the Peace and Conflict Studies Center Asia (PACSC Asia) hosted a two-day problem-solving workshop (PSW) on the IGC Korea Campus in Songdo with 14 members of South and North Korean communities living in South Korea. The workshop is a well-established practice in peacebuilding and conflict resolution that provides an informal, low-risk, noncommittal forum in which unofficial representatives can privately analyze different issues, identify problems, and engage in active problem-solving processes. ${ }^{2}$ The purpose of the workshop was to generate key insights and perspectives from North and South Koreans living in South Korea on the best ways to deal with integration and coexistence issues as the process of reunification moves forward. The workshop offered a safe place for North Korean diaspora members to share their experiences and to connect with others who have faced similar challenges while adapting to South Korean society. The participants discussed relevant issues in an informal, discreet, safe, and low-profile context.

The PSW was hosted over a period of two days. It consisted of lectures, group work, and structured exercises and discussions that provided concrete ideas on the major issues and strategies of problem-solving that could serve to inform policy of future peacebuilding efforts and contribute to communal resilience to conflict. Together with colleagues and students, the workshop was facilitated by Dr. Borislava Manojlovic, who created specific program activities to help the participants analyze and identify problems, generate solutions, build teams, and use

2 Dean Pruitt, Sung Hee Kim, and Jeffrey Z, Rubin, Social Conflict: Escalation, Stalemate, and Settlement (Boston, MA: McGraw-Hill, 2004). 
conflict resolution skills to gain deeper insights into the core issues and propose creative ideas. George Mason students from PACSC Asia worked as translators, discussion leaders, note-takers, and logistics staff during the workshop.

A bigger pool of workshop participants would be necessary to claim the statistical significance of the results. However, this study's contribution is in its preliminary findings, generated through a unique venue-problem-solving workshops -in which participants from both communities have been able to interact face-to-face and lead an in-depth discussion about key issues. The venue for free and open discussions between the two communities in Koreas has been almost non-existent. Therefore, PSWs provided a unique and safe locale to generate both the qualitative and quantitative data on a smaller sample, which offered the initial insight into the communally identified issues. While the sample has been limited, the scope and depth of the collected data have been substantial. This study's findings show that people's perceptions towards the other are primarily shaped through intercommunal interaction and quality contact can significantly impact future relations in communities.

\section{Literature Review}

Before delving into the data collected during the PSW, it is important to discuss research that has already been done on the relationship and attitudes of North and South Koreans towards each other and the possibility of integration. Kim and Jang bring insights into the increasing apathy South Koreans feel towards North Koreans living in the South. ${ }^{3}$ The national poll of the Korean Institute for National Unification in 2005 indicated that South Koreans were experiencing lower degrees of compatriotism and animosity towards North Korean refugees compared to previous years' results. Most of them reported having "no particular emotion" towards the other. On the other hand, North Koreans living in South Korean society reported feeling "emotionally distant" from their South Korean neighbors. The authors explained that such indifference towards one another could often bring about mutual distrust, and cases where South Koreans have committed fraud against North Koreans, have only reinforced North Koreans' negative image.

Cho's article analyzes South Korea from the North Korean perspective in three ways. First, South Korea's "imagined self" is seen as inseparable from North Korea. ${ }^{4}$ The phrase "We, the same Korean" summarizes the view that North Koreans emphasize the historical roots shared with the South Koreans. The second image of South Korea is the "tainted but strong self," in which South Korea is looked upon as a society that needs to be rescued from the U.S. imperi-

3 Jihun Kim and Dongjin Jang, "Aliens among Brothers? The Status and Perception of North Korean Refugees in South Korea," Asian Perspective 31, no. 2 (2007): 5-22.

4 Young Chul Cho, "North Korea's Nationalistic Discourse: A Critical Interpretation," Korea Observer 42, no. 2 (Summer 2011): 311-43. 
alism. North Korean media often describes South Korea as being a colony of the Western world.

Consequently, the people of the South are viewed as naive and oblivious. Lastly, South Korea is considered to be the "threatening other" that possesses dangerous and hostile qualities that challenge the North Korean regime. It is important to keep in mind that the images North Korea portrays about the South have been communicated and censored by the North Korean government, but there is a gap in knowledge about the views of the people of North Korea themselves about their Southern counterparts.

According to data from public opinion surveys conducted by the Asian Institute for Public Studies, there seem to be different generational perceptions among South Koreans towards North Koreans. ${ }^{5}$ More negative perceptions were reported to be stronger among those in the 20s and the elderly (60s and over). The in-between age groups generally saw North Koreans as "neighbors" and "one of us," while the younger and older generations perceived them as "enemies" or "strangers." A closer look at the survey results revealed that many young people in South Korea oppose the government's funding to North Korea and do not feel empathy for the socio-economic situation of the majority of the people there. Moreover, there is a general fear among those in the 20s and the elderly that a war could break out at any time between the two Koreas. Based on that belief, their image of the other has been primarily shaped by mistrust and apprehension.

The mistrust among the two communities has also been portrayed on some popular television shows. For example, On Our Way to Meet You is a television program in South Korea in which North Korean refugees are invited to speak about their experiences living and adjusting in the South. In an episode titled, "South Korean Stereotypes towards North Koreans," ${ }^{6}$ former North Koreans emphasized that they were often perceived as the Kim regime's supporters. One of the interviewees shared that whenever news headlines about the North Korean missile tests were released, his neighbors would criticize and shun him just because he was from the North. However, he pointed out that the regime and the people were not "one." From their testimonies, it seemed that the South Korean image of the North Koreans has been heavily dependent on how they felt about the Kim regime and their behavior fluctuated from extremely bellicose to mildly aggressive. In contrast to the South Korean belief that everyone in the North had some degree of loyalty to the Kim regime, North Koreans wished to be perceived as individuals with their own views and stance.

The literature review shows that much of the intercommunal perceptions have been affected by the daily events and public discourse coming from the

5 Ji-yoon Kim, Chung-ku Kang, and Kil-dong Kim, "To South Korean Youth, North Korea Is Not 'One of Us'," The Korea Times, May 1, 2018, www.koreatimes.co.kr/www/ nation/2018/05/103_248242.html.

6 "South Korean Stereotypes towards North Koreans," On Our Way to Meet You, Channel A, September 10, 2017. https://tv.naver.com/v/2048839. 
media, news, and other public platforms rather than through face-to-face interaction. However, this study's findings show that the perceptions of people towards the other are primarily shaped through interaction rather than media. Although the current political situation makes it difficult for interaction to take place between North and South Koreans across the state borders, efforts towards a peaceful integration can begin through interaction with North Korean diaspora members that are already in South Korea. As findings of this study demonstrate, the high levels of uncertainty and distrust about the other could be addressed by increased quality contact and education that promotes understanding, tolerance, and respect.

\section{Participants}

There were fourteen participants in the workshop. The majority of participants, ten, belonged to the North Korean diaspora, while four were members of the host South Korean community. The participants were recruited through contacts with non-governmental organizations, educational institutions, and ads posted on social media platforms. Since the participants had varying degrees of fluency in English, simultaneous translations were provided by GMU Korea students throughout the sessions. In terms of gender and age, there were ten women and four men; eight participants belonged to the 18-35 age group, while 6 participants belonged to the 36-60 age group. In terms of educational level, the majority of participants had a Bachelor's degree.

\section{Data Collection}

The problem-solving workshop with North Korean diaspora members and their South Korean counterparts served as an opportunity for the two communities to engage actively and to assess communal resilience to conflict. The PSWs focused on identifying issues that communities face in their everyday interaction and how they dealt with differences. The data was collected via a survey and through problem-solving exercises. To elicit more detailed, qualitative responses, the participants were divided into three groups, with approximately five members who participated in the "problem-solving tree" exercises. Each group created its own tree identifying major issues that they placed on the tree trunk. Then they listed the causes, and finally, they linked the issues to the outcomes in the tree branches.

The participants were given an ample amount of time to construct a tree on the topic of conflict resilience and integration as a group, and the results were shared with the participants the next day. The collected data was analyzed by examining the indicators of the three aspects of resilience at the micro-level: 1) recognition of communal and individual interdependence and integration, 2) quality of interaction, and 3) perceptions promoting cooperation and trust. 


\section{Data Analysis}

\section{Problem Solving Exercises}

In this section, I examine the issues, root causes, and outcomes identified by the participants in the problem-solving exercises. Many of the issues related to difficulties in achieving peaceful co-existence and integration have to do with cultural differences between North and South Koreans. Although the two communities share a common history and ethnic tradition, the 70-year long separation under very different governing systems has resulted in a cultural divide. The differences in communication styles have been cited as one of the important challenges that the communities faced. For instance, North Koreans tend to be more direct, and they tend to speak with candor, while South Koreans are more indirect and use high-context language, which shows their socio-economic status, position, and age group.

Another issue indicating cultural differences was the sharing and cavalier attitude among North Koreans. For North Koreans, "going Dutch" seems rather "cold-hearted," detached, and even rude. While it is common among South Koreans to settle their bills by paying separately or splitting the amount owed, the North Koreans are more used to taking turns to buy meals or repaying someone through other means. The "culture shock" North Koreans experience upon arriving in South Korea is similar to the experience of a foreigner coming to Korea. One participant points out that "The mental and emotional challenges we experience resemble the types of trouble third culture kids (TCKs), like missionary kids, go through upon repatriation." The different cultural, communication and language practices in communities' daily lives reveal a lack of communal and individual interdependence and integration, which may negatively affect communal resilience to conflict.

Other issues that were brought up by participants revealed the lack of trust that both communities face at the personal and relational level. For instance, North Koreans pointed out that they have interacted and engaged in conversations with their South Korean neighbors daily, yet they felt as if there was still a 'wall' between them that they could not overcome. One North Korean participant used the term 'orientalism' to explain South Korean attitudes towards him when they first learned that he had "defected from the North." The North Korean participants pointed out that there was a perception about them being 'uncivilized,' 'uneducated,' 'unrefined' or even that they were "the recipients of too much sympathy" because of the intense trauma they must have acquired living under the Kim regime. By contrast, most of the North Korean participants in the workshop possessed at least Bachelor's degrees, and many of them were studying to earn a Master's degree in South Korea. Furthermore, some came from rather wealthy backgrounds and did not describe their lives in North Korea as 'traumatic.' As one participant pointed out, "North Korean collectivism is stronger than South Korean collectivism." By this, he meant that North Korean attitude towards the Korean culture and identity was more conservative and old- 
fashioned. He also spoke of North Koreans' need to belong to the ingroup, which provided safety, while outsiders were generally distrusted not only because they have lived in isolation before coming to the South, but also because they saw South Koreans as more Westernized and therefore by default less trustworthy.

According to the participants, the root causes that have created the conditions for inter-communal distrust and stereotypes include North Korea's isolation from the rest of the world and the generational gap that prevents South and North Koreans from having a consistent attitude or knowledge about the other. An important finding was that the perceptions of South Koreans toward the North Korean diaspora were based on the lack of information and knowledge that can only come from face-to-face interactions. This led to the formation of stereotypes and distrust, which can pose a challenge to communal resilience and sustainable peace.

The language spoken in South Korea is full of recently adopted westernized words, which North Koreans find not only difficult to understand but also difficult to accept. For example, some of the everyday South Korean words adopted from English, such as 'nickname,' 'personality,' and 'tour' have their equivalents in Korean, but people in South Korea prefer using the westernized version. As mentioned in the literature review, South Koreans' young generation showed very little interest in co-existence and living together with their North Korean counterparts. The participants argued that the lack of interest was connected to poor education with regards to integration among youth. As one participant pointed out:

... the voices on the coexistence and integration of the Two Koreas that are constantly heard are the voices of the international bodies and South Korea, but voices and perspectives that come from North Koreans or young people are not heard.

Therefore, an eventual peaceful solution and reunification cannot become a reality until all current and future stakeholders are given a voice on the matter.

Due to the social, economic, and cultural differences of being raised in different systems, there has been an acute lack of understanding among community members that often resulted in negative perceptions and distrust towards the other. However, individual members of both communities have constantly been trying to balance their personal and collective selves, especially when facing a perceived threat. They had needed to differentiate from the group to preserve parts of their individual uniqueness and identity, especially when their group identity was not considered advantageous. As one of the participants expressed, "North Koreans are not all the same. We want to be seen as different entities from our leader and his regime." In other words, the South Koreans' perception that all North Koreans were "the children of Kim Jong-un" and the North Koreans' perception that all South Koreans were "cocky, selfish, and passive" have been a hindrance towards improving the relationship between the two groups. This phenomenon is called a 'unitary trap,' which refers to the tendency of putting a whole group of people in one box that locks the communities in an identity 
struggle. The way out of the unitary trap is by exposing stereotypes, inaccuracies, and rumors, which is the key step towards achieving conflict resilience.

\section{Survey}

Survey data provided some additional insight into the perceptions of North and South Koreans about each other. The finding from the PSW exercises that personal interaction was the key factor that shaped participants' attitudes towards the other was confirmed in the survey by most participants (see Table 1).

\section{Table 1. What Shaped Your Attitude towards South/North Koreans?}

\begin{tabular}{|c|c|c|c|}
\hline \# & Answer & $\%$ & Count \\
\hline 1 & Personal interaction with them & 50 & 8 \\
\hline 2 & News and documentaries & 18.75 & 3 \\
\hline 3 & Political ideology & 12.5 & 2 \\
\hline 4 & $\begin{array}{l}\text { Entertainment media (movies, } \\
\text { music, arts, sports, etc.) }\end{array}$ & 6.25 & 1 \\
\hline & Total & 100 & 14 \\
\hline
\end{tabular}

The majority of both South and North Korean participants ( $82 \%$ ) pointed out that the words that best describe their perception about the other group were "one of us" and 'neighbor,' while $16 \%$ of the participants perceived the members of the other group as 'strangers' (see Table 2).

Table 2. Which Word Best Describes Your Perception towards South/ North Koreans?

\begin{tabular}{r|l|c|c}
$\#$ & Answer & $\%$ & Count \\
\hline 1 & One of us & 41.67 & 5 \\
\hline 2 & Neighbor & 41.67 & 5 \\
\hline 3 & Stranger & 16.67 & 2 \\
\hline 4 & Enemy & 0 & 0 \\
\hline 5 & Not applicable (neutral) & 0 & 0 \\
\hline & & 100 & 12
\end{tabular}

The participants identified the others as 'strangers' because there were differences in language, culture, and background, while the majority stressed that because they all currently lived in the South, it was natural to think that "we were one." South Korean participants pointed out the difference between North Koreans living in the South and those in the North: 
Because of the personal interactions I have had with the North Korean diaspora, I feel as if we are one. However, I only feel that towards the North Koreans who are in South Korea. For those who are in the North, I would consider them foreigners.

When asked about the future life together and co-existence, $50 \%$ of the participants were neutral, and $50 \%$ agreed that the future together was possible (Table 3 ). This is an interesting finding that points to the ambiguity about the status of their nations and distrust that exists among communities. According to the participants, the main obstacles to integration and life together have been the regime in North Korea, failed negotiations, access to information about each country, and cultural differences. The positive aspects of integration have been the same - language, the same national roots, Confucian cultural practices, and history that bound the Korean Peninsula people for centuries.

Table 3. In the Future, Is It Possible for North and South Korea to Peacefully Coexist?

\begin{tabular}{|c|c|c|c|}
\hline$\#$ & Answer & $\%$ & Count \\
\hline 8 & Strongly agree & 7.14 & 1 \\
\hline 9 & Agree & 42.86 & 6 \\
\hline 10 & Neutral & 50 & 7 \\
\hline 11 & Disagree & 0 & 0 \\
\hline \multirow[t]{2}{*}{12} & Strongly disagree & 0 & 0 \\
\hline & Total & 100 & 14 \\
\hline
\end{tabular}

However, common national and ethnic identity has not been strong enough an incentive for participants to agree on the possibility of peaceful co-existence of the two states. While most of the participants considered North and South Koreans the same nation (See Table 4), both communities are ambiguous and unsure if the two nation-states could coexist.

Table 4. Do You Think North and South Koreans Are the Same Nation?

\begin{tabular}{l|l|c|c}
$\#$ & Answer & $\%$ & Count \\
\hline 1 & Strongly agree & 50 & 7 \\
\hline 2 & Agree & 42.86 & 6 \\
\hline 8 & Neutral & 7.14 & 1 \\
\hline 9 & Disagree & 0 & 0 \\
\hline 10 & Strongly disagree & 0 & 0 \\
\hline 11 & Other & 0 & 0 \\
\hline & & $100 \%$ & 14 \\
\end{tabular}


The participants' qualitative responses showed that the nature of the two states was so different that even the people who belonged to the same ethnic and cultural background could not see the two systems working either side by side or unified unless there was a major ideological change.

Another interesting finding from the survey was that the majority of the North Korean defectors felt that they were discriminated against in South Korea (see Table 5). ${ }^{7}$

Table 5. Have You Ever Experienced Discrimination in South Korea as a North Korean?

\begin{tabular}{|r|l|c|c|}
$\#$ & Answer & $\%$ & Count \\
\hline 1 & Strongly agree & 12.5 & 1 \\
\hline 2 & Agree & 50 & 4 \\
\hline 3 & Neutral & 25 & 2 \\
\hline 6 & Disagree & 0 & 0 \\
\hline 7 & Strongly disagree & 12.5 & 1 \\
\hline & & 100 & 8 \\
\hline
\end{tabular}

Misunderstanding was often due to the difference between Hangul language in South Korea, with its large influx of the Western vocabulary, and the North Korean dialect, which emphasized the purity of language. One participant argued:

I have constantly heard them talk about North Korean defectors in derogatory terms and question our true motives of coming down to the South. People's tone of voice changes when they realize they are talking to a North Korean defector which immediately puts us in a disadvantaged position during job interviews and public engagements.

Another participant confirmed the previous point by stating: "When I told the principal of my child's kindergarten that I am a North Korean defector, her attitude changed. She became cold and unkind."

When asked about their hopes and goals for the future, the North Korean participants mentioned the importance of non-discrimination and living freely in South Korea. While the hopes of the South Koreans were broader and more general, North Koreans seemed to have more specific hopes and dreams that ranged from better care for their elderly and building the unification education system

7 Note that the overall number of responses for different questions is different because the participants skipped some questions in the survey. For example, despite there being 14 participants, only 8 or 12 responded to a certain question. Moreover, some questions (Table 5) were only directed to the particular community, e.g., North Koreans. 
in South Korea to visiting their hometowns and families in North Korea. Both groups had great hopes that the pain of division and parted families would be addressed in the near future.

\section{Findings and Conclusions}

Conversations on co-existence, resilience, and integration are limited to very few spaces in the current South Korean society. Despite having the same ethnic and cultural background, North and South Koreans cannot see the two political systems working either side by side or unified unless there is a major political and social change, especially in North Korea. Over 30,000 North Korean defectors currently living in South Korea have been a constant reminder that there was the other society just a few miles from Seoul that has driven those defectors out and compelled them to the life of refugees. In the new society, the North Koreans often face difficulties as they try to be accepted and understood by their hosts. The different cultural, communication, and language practices in the daily life of communities reveal that there is a lack of interdependence and integration.

This study also shows that the perceptions of people towards the other are primarily shaped through interaction. Quality interaction is much needed to promote equity and unbiased attitudes. Increased contact and cooperation among North and South Korean communities through platforms such as the PSWs can strengthen the capacity for collaboration and conflict resilience at the communal level, which is a pre-condition for the larger process of integration. As stated by Allport's Contact Hypothesis, ${ }^{8}$ intergroup relations can be improved through quality contact under appropriate circumstances. Quality contact may challenge the initial prejudice that has been creating misunderstanding, miscommunication, and irrational fear of the other. ${ }^{9}$

Since conflict resolution practice is still relatively new to Korea, there is a need for more experts and activists who are willing to engage communities and do the work at the grassroots level. Having expert facilitators who understand the local needs, context, and situations to conduct future workshops and dialogues should remain a priority. Although the current political situation makes it difficult for interaction to take place between North and South Koreans across the state borders, efforts towards a peaceful co-existence can begin through interaction with North Korean diaspora members that are already in South Korea. As findings of this study show, the high levels of uncertainty and mistrust about the other could be addressed by increased quality contact and grassroots education that promotes understanding of cultural differences, tolerance, and respect.

8 Gordon W. Allport, The Nature of Prejudice: 25th Anniversary Edition, Unabridged (New York: Basic Books, 1979).

9 Buhle Zuma, "Contact Theory and the Concept of Prejudice: Metaphysical and Moral Explorations and an Epistemological Question," Theory \& Psychology 24, no.1 (2014): 40-57. 
Apart from quality interaction, the education system would benefit from incorporating a new curriculum on reunification to primary and secondary schools in South Korea. The purpose of the reunification education is not to force students to think that reunification is necessary and must happen at all cost, but to encourage them to think for themselves about the future and the role they might want to play in the process of building peace.

One of the most interesting aspects of the workshop was the impassioned participation of both South and North Koreans in the discussions. People were eager to express their views and they ardently communicated their thoughts. Moreover, they were not afraid to ask questions to others and the facilitators. The participants did not seem intimidated or uncomfortable in a new setting, and they were happy to share their stories openly. Although the overall impact of the PSW could not be measured at this point, the participants found this format empowering. Talking about their experiences, the participants exemplified resilience, strong will, and perseverance. In this way, they were able to organize their memories, process emotions, and make sense of who they are.$^{10}$ Since the goal of the PSW was not to come up with direct solutions or answers but to foster understanding and recognize the key issues, the workshop empowered the participants by providing a safe space for them to share their stories.

\section{Disclaimer}

The views expressed are solely those of the author and do not represent official views of the PfP Consortium of Defense Academies and Security Studies Institutes, participating organizations, or the Consortium's editors.

\section{Acknowledgment}

Connections: The Quarterly Journal, Vol. 19, 2020 is supported by the United States government.

\section{About the Author}

Borislava Manojlovic, PhD, is the Assistant Professor at the Carter School for Peace and Conflict Resolution, George Mason University. She is an expert in peacebuilding, transitional justice, dealing with the past, peace education, and atrocities prevention. Before joining academia, she worked on minority and reconciliation-related issues with the United Nations and the Organization for Security and Cooperation in Europe in both Croatia and Kosovo for over seven years. Her book Education for Sustainable Peace and Conflict Resilient Communities, was published by Palgrave Macmillan in 2018. Prof. Manojlovic received her master's degree from Brandeis University and her doctorate from George Mason University's Jimmy and Rosalynn Carter School for Peace and Conflict Resolution. E-mail: bmanojlo@gmu.edu

10 Nader Amir, Jane Stafford, Melinda S. Freshman, and Edna B. Foa, "Relationship Between Trauma Narratives and Trauma Pathology," Journal of Traumatic Stress 11, no. 2 (1998): 385-392. 